\title{
Conservation crisis - the rhinoceros in India
}

Esmond Bradley Martin, Chryssee Bradley Martin and Lucy Vigne

The greater Indian rhinoceros, on the verge of extinction in India 80 years ago, has recovered dramatically with conservation help. In 1980 there were 1250 in the country. At about that time, however, poaching suddenly started to become a serious problem, and since then over 200 animals have been killed. The authors explain why and suggest how this reverse could be stopped.

The spectacular increase of the greater Indian rhinoceros Rhinoceros unicomis population has been a major achievement in the world of conservation. At the turn of the century the species had been almost eliminated from India: only an estimated 12 remained in 1908 in the Kaziranga area of Assam, plus a few in scattered places (Laurie, 1978). However, with the establishment of protected areas for the rhino in Assam and West Bengal (Figure 1) and the implementation of a good management programme, the number of rhinos increased from fewer than 50 in 1910 to 1250 in 1980 . The only other substantial population is in the Royal Chitwan Park, Nepal, where there are about 375 today.

The disappearance of most of India's rhinos by the beginning of this century was due not so much to sport hunting - although the Maharajah of Cooch Behar boasted of having shot 207 between 1891 and 1907 - as to the government bounty of Rs20 for killing a rhino; the thought of a rhino rampaging a tea plantation was anathema. Now the reverses in rhino conservation are being caused by poachers. In 1986 only about 32 rhinos were left in West Bengal and 1295 in Assam (Table 1). Poachers killed at least 233 rhinos in Assam between 1982 and 1985 (Table 2).

\section{Poaching in Assam}

Assam's 430-sq-km Kaziranga National Park 212 holds 80 per cent of the world population of greater Indian rhinos. An average of five rhinos a year were poached there between the mid-1960s and 1980 , but this had little impact on the steadily rising population: 400 in 1966, 670 in 1972 and 960 in 1978 (Lahan, 1984). Then, in 1982, there was a partial breakdown in law and order in Assam. Political disturbances, clashes among various ethnic groups, and the resultant deaths of 3000 people meant that the authorities were too

Table 1. Estimated wild populations of the greater Indian rhinoceros in 1986

\begin{tabular}{|c|c|}
\hline Country & Numbers \\
\hline \multicolumn{2}{|l|}{ India } \\
\hline \multicolumn{2}{|l|}{ Assam } \\
\hline Kaziranga & 1080 \\
\hline Manas & 80 \\
\hline Orang & 65 \\
\hline Pobitora & 40 \\
\hline Laokhowa & 5 \\
\hline \multirow[t]{2}{*}{ Other pockets } & 25 \\
\hline & 1295 \\
\hline West Bengal & 32 \\
\hline \multirow[t]{2}{*}{ Dudhwa (reintroduced from Kaziranga) } & 7 \\
\hline & 1334 \\
\hline Nepal & 375 \\
\hline \multirow[t]{2}{*}{ Pakistan } & 2 \\
\hline & Total: 1711 \\
\hline
\end{tabular}




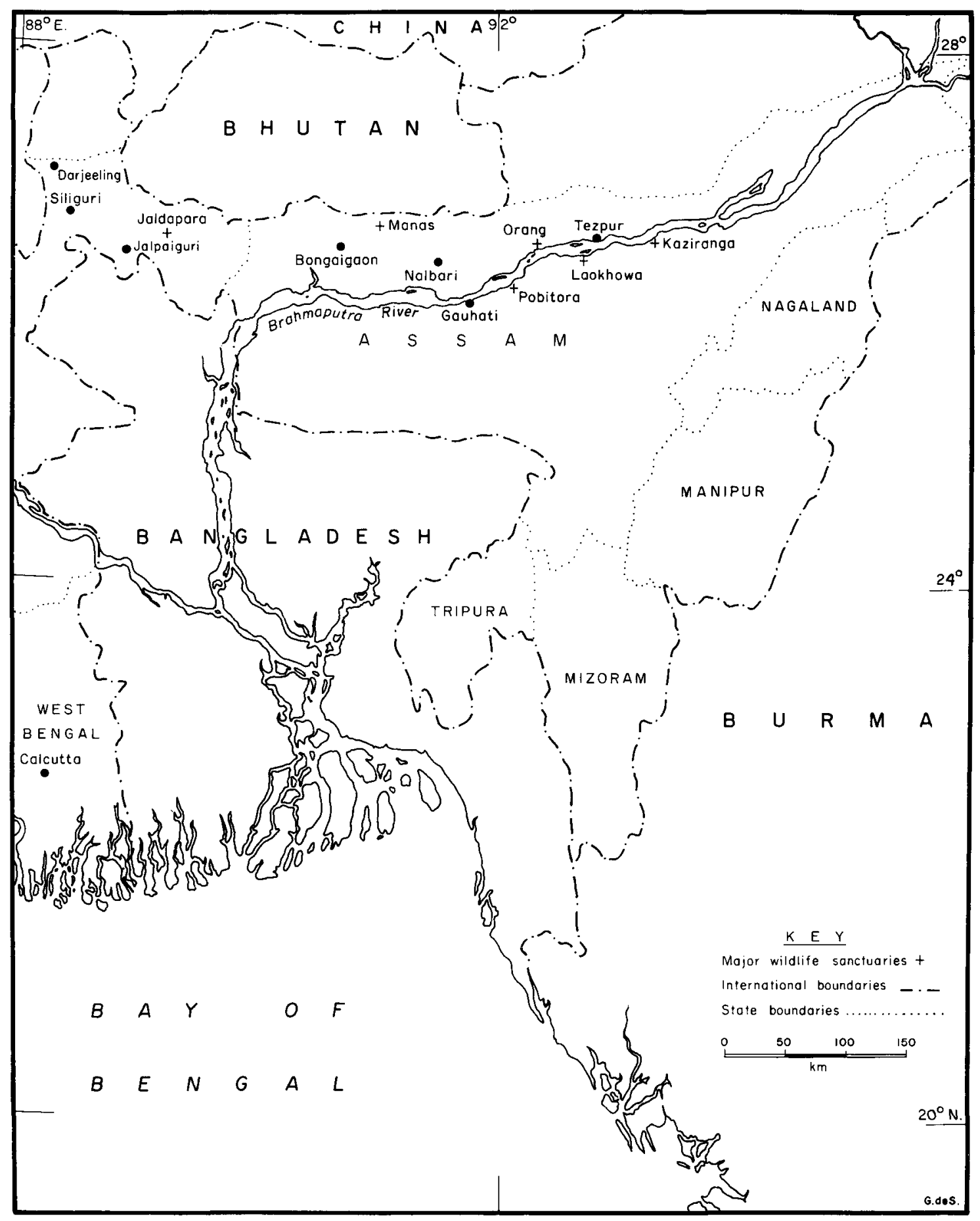

Figure 1. A map of North East India showing the major wildlife sanctuaries. 
involved in trying to quell violence to help wildlife personnel engaged in anti-poaching activities. Poaching gangs invaded the main rhino sanctuaries of Kaziranga, Manas and Orang, and almost wiped out the entire adult rhino population in Laokhowa Wildlife Sanctuary.

Poaching is usually organized by a syndicate of middlemen, who recruit two or three individuals to hunt a rhino together. They buy them food and drink, offer a little money in advance and, for poaching in Kaziranga, supply a modern rifle and a few cartridges. Until 1980 most of the rhinos killed in Kaziranga had been caught in pit traps, which required intricate knowledge of the terrain, were time-consuming to build, and needed regular checks. Rifles were not available, and the use of a shotgun with homemade heavy bullets was risky. However, the .303 and 7.62 rifles that syndicates now obtain in Nagaland (from Nagas who have purchased them from neighbouring countries) have revolutionized poaching in Kaziranga. While the Nagas have no tradition of killing rhinos, the syndicates now recruit some of these people for poaching gangs in order to have access to their weapons. Moreover, there are also now more Assamese malcontents, unemployed and under-employed, who have become illegal hunters, lured by the prospect of fortune, according to P. C. Das, former Chief Conservator of Forests in Assam.

A small group will enter the park very early in the morning or just after dusk. They have little difficulty in doing this undetected because many people live on the park boundaries. After shooting a rhino, they remove its horn and, if there is time they cut off some skin and meat.
They take the horn to the middleman responsible for organizing the gang, who pays them Rs20,000-25,000 for an average size horn of $750 \mathrm{~g}$, according to P. Lahan, Director of Kaziranga National Park, who obtained this information from captured poachers. This is about the equivalent of $\$ 2600$ per kilogram.

In Manas Wildlife Sanctuary there are only 7580 rhinos in an area of $390 \mathrm{sq} \mathrm{km}$, and a poaching gang spends much more time inside. In the winter, when Manas is dry, a gang may camp for several nights near a wallow, waiting for a rhino, which is killed with a muzzle-loader or a shotgun. These poachers are Bodo-speaking people who have a long tradition of rhino hunting and have uses for several rhino products. They generally sell the horn to a middleman, however. In the early 1980 s they were paid about $\$ 1200$ a kilogram for it according to S. Deb Roy, Field director, Project Tiger Manas, but occasionally the price was considerably higher.

In March 1986 we interviewed a former Bodo rhino poacher in Manas. In February 1982 he had joined a gang of three other small-scale farmers who went into Manas Sanctuary to hunt a rhino. The gang had not received any advanced financial support from a middleman, but a wealthy Assamese merchant in Simla Bazar, some $45 \mathrm{~km}$ away, had offered to pay them the equivalent of $\$ 4000$ a kilogram for a horn. Inside the sanctuary they built machans (elevated platforms) over rhino paths and near wallows, usually dismantling them by morning in case they were noticed by the Forest Guards. When they finally killed a rhino, with a 12 bore shotgun, it took them an hour to remove its horn with an axe, and they also

Table 2. Number of known rhinos poached in Assam

\begin{tabular}{|c|c|c|c|c|c|c|c|}
\hline Area & 1979 & 1980 & 1981 & 1982 & 1983 & 1984 & 1985 \\
\hline Kaziranga National Park & 2 & 11 & 25 & 26 & 37 & 25 & 41 \\
\hline Near Kaziranga National Park & - & - & - & - & - & 3 & 1 \\
\hline Laokhowa Wildlife Sanctuary & 6 & 1 & 6 & 5 & 40 & - & - \\
\hline Manas Wildlife Sanctuary & 5 & 3 & 2 & - & 3 & 5 & 2 \\
\hline Orang Game Reserve & 2 & 4 & 2 & 5 & 4 & 4 & 8 \\
\hline Pobitora Reserved Forests & - & - & - & - & - & 4 & 2 \\
\hline Other places in Assam & - & 3 & 4 & 8 & 7 & 3 & - \\
\hline Grand total & 15 & 22 & 39 & 44 & 91 & 44 & 54 \\
\hline
\end{tabular}

Source: Chief Conservator of Forests, Assam. 


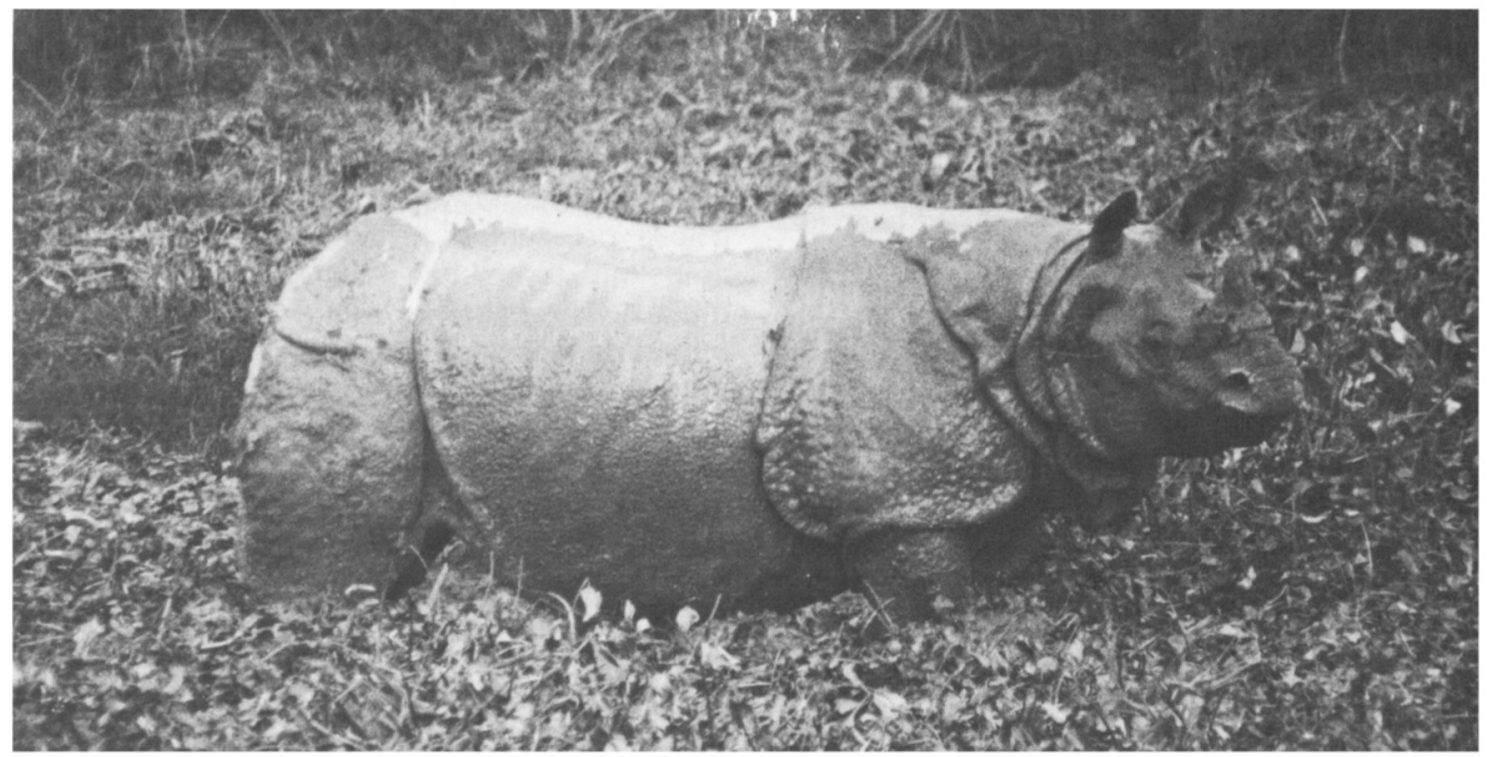

Indian rhinos often return to the same wallows - a practice that makes them vulnerable to poachers (Lucy Vigne).

removed some meat, hide, teeth, the toe-nails and the tip of the tail. Retreating as quickly as they could, they went to Simla Bazar where the merchant paid them the agreed price without any bargaining. The gang divided the money, with the largest amounts going to the man who handled the gun and the one who had obtained the cartridges. In their village they sold the toe-nails for $\$ 5$ each. One of the gang kept the tail for good luck, and the teeth were placed in a rice granary for the same purpose. The gang made a meal from the meat, of which the liver was considered to be the main delicacy.

In the Orang Game Reserve, which is only $76 \mathrm{sq}$ $\mathrm{km}$ and had 65 rhinos in 1985 (Bhattacharjee, 1985), pit trapping for rhinos started in late 1984; prior to that firearms were used, but in the early 1980s members of the Forest Department and police raided the houses of suspected poachers and confiscated many guns. Gangs of up to five men dig a hole $2 \mathrm{~m} \times 1 \mathrm{~m}$ along a regular rhino path, covering it with grass. Although it is timeconsuming constructing a pit, staff of the reserve cannot readily detect one and there is no sound of gunshot to alert them. In 1984 and 198512 rhinos were caught in this way, and if the practice continues there will soon be no rhinos left in Orang. The main reason for the increase in The rhinoceros in India poaching here is the high price offered for the horn. R. Bhattacharjee, the Divisional Forest Officer, Western Assam, said that the poachers (Assamese, Nepalese and immigrant Muslims from Bangladesh) were being offered $\$ 3000$ a kilogram in late 1985 and early 1986. The poachers remove only the horn.

\section{A threat from Bhutan}

Besides the illegal killing of rhinos in Assam and West Bengal by poor farmers in quest of money, there have been two instances when prominent individuals have shot Indian rhinos. The King of Nepal killed one on the outskirts of the Royal Chitwan Park in 1981 for religious reasons (Martin, 1985), and in December 1979 the King of Bhutan shot one simply for sport. At that time the Indian authorities in Manas were aware that the King's hunting party was just across the river frontier and they set off firecrackers to frighten away the wildlife. However, one of the rhinos the Forest Guards were trying to protect was confused by the noise and headed off in the wrong direction. Crossing the river at night, it went to the salt lick where the hunting party was waiting and was shot immediately. Its horn and toe-nails were removed, but the rest of the carcass was buried. 
The King then left, but next morning the Manas guards suspected that something was wrong from the way the Bhutanese were behaving. They went to the salt lick, discovered the burial place and dug up the rhino. The incident particularly annoyed them because the animal had been one of their better-known rhinos. The Assam Forest Department believes that this was the only rhino shot by any member of the Bhutan royal family for several years, but they feel that the King set a very poor example to the Bhutanese elite, and they are very worried that it might happen again since the rhinos do cross the river.

\section{A lack of manpower}

Much of the poaching in Assam would be curtailed if only the reserves had more manpower. The Forest Guards are generally very reliable and hard working, but there are too few of them and they do not have sufficient transport or weaponry to combat the onslaught of poaching. In the early 1980s the situation became acute, with the settlement of more people around reserve boundaries. In March 1986 the Range Officer of the central portion of Kaziranga complained that he had only half the number of staff he needed to be able to deal with the problems resulting from the recent infiltration of syndicated middlemen into surrounding villages, who were encouraging the inhabitants to kill rhinos by offering them high prices for horn. In Orang there are only 32 men in anti-poaching patrols; they have to work out of 14 camps, but have only two domesticated elephants to help with transport. Elephants are ideal for moving silently through the bush, but the Forest Department requires many more for adequate patrolling of the rhino sanctuaries.

Long periods of separation from their families, poor living conditions and difficulties in obtaining provisions - especially during the monsoon are hardships that Forest Guards usually have to bear; they accepted them until poaching became rife, but now their morale is low, particularly in Manas and Kaziranga. Almost incredibly, two Forest Guards in Kaziranga joined a poaching gang, which killed a rhino; they were caught and arrested, but the fact that they became involved is ominous.

\section{A problem of law enforcement}

Although the law against poaching is strict, its enforcement is a problem. Unscrupulous lawyers are hired by the syndicates for an arraigned poacher, and they are often more skilled than the public prosecutors, arguing for long delays in court and sometimes bribing witnesses to testify against the charges. Because of the procrastination and the syndicates' financial assistance, few poachers see the inside of a prison.

It is especially difficult to catch the worst offenders, the Marwari, Bengali, Nepalese and Assamese middlemen belonging to the syndicates that handle the rhino horn trade. Between poacher and exporter there is a chain of at least three, but often as many as ten, individuals. If the authorities entrap one, he rarely knows even the name of his next contact in the chain, let alone that of the head of the syndicate. Moreover, middlemen have been told that if one of them is sent to prison the syndicate will provide sustenance for his family if he does not talk.

\section{Where is the horn going?}

Thus, obtaining information on how rhino horn leaves Assam and learning its destination is a task some authorities regard as impossible. It is known, however, that although Nepalese often act as middlemen they do not send the horn to Nepal. The only horn for sale in that country is in the form of very small antique carvings for religious purposes.

If the horn from India is not being exported to Nepal, where is it going? From Manas Sanctuary it is moved into the nearby villages of Bongaigaon, Khusratari and Mazrabari, and from there is transported to Siliguri and Jalpaiguri in West Bengal or to Kalimpong, near Darjeeling, according to S. Deb Roy and the Range Officer of Manas, M. S. K. Sharma. From these places it moves on to Calcutta. In the Kaziranga area, rhino horn is sent to Gauhati, Nagaland and then on to Calcutta, according to police who have interrogated poachers. Orang rhino horn also moves through West Bengal down to Calcutta. Not very long ago the police seized a rhino horn on a bus on the way from Tezpur (near Orang) to Siliguri. The trader carrying it confessed that the Oryx Vol 21 No 4, October 1987 
horn was supposed to proceed onward to Calcutta, where perhaps over 90 per cent of all rhino horn from Assam eventually ends up before being exported.

On account of the very high prices, around $\$ 8000$ per kilogram wholesale in India, hardly any of it remains in the country. Only minute quantities are used in Assam for making rings and lockets. In 1980 (Martin, 1983) and in 1986 we visited Bombay, Ahmedabad, Delhi, Patna, Lucknow, Calcutta and Hyderabad, but found no Indian rhino horn for sale in any traditional medicine shop.

Until late 1986 most Indian rhino horn ended up in Singapore where there were no restrictions on its import, and where it fetched very high prices. It was usually smuggled out by sea, security being much tighter at Calcutta's Dum Dum airport. Traders in South East Asia have confirmed that Indian rhino horn was routed from Calcutta to Singapore, and they also admitted to paying about $\$ 9000$ a kilogram for it there.

The Indian Customs officials cannot examine thoroughly every single shipping consignment and piece of luggage leaving India from Calcutta, but when they have a lead they follow it very closely. For instance, in early 1985 government officials put a lot of effort into trying to catch one particularly important dealer. The man, a Marwari resident of Calcutta, took six Indian rhino horns out of Dum Dum airport and flew to Hong Kong. There he was intercepted by officials from the Agriculture and Fisheries Department, who discovered the horns in his luggage. They would not allow him to proceed to his destination, Macao, forcing him instead to take a flight to Bombay. On the way he disembarked in Singapore and probably sold the horns. He never went to Bombay, but some months later he went to a wedding in Calcutta and was arrested and jailed. According to Indian officials this is the first case in which a major rhino horn exporter has gone to prison in India.

\section{What needs to be done?}

The present rhino conservation problems in India are not insurmountable. Assam has an excellent The rhinoceros in India reputation for protecting its wildlife, and the Forest Department in charge of its management is headed by dedicated and efficient personnel. Rhino poaching was kept at a low level until only recently, but, now that it has become serious, improvements are required and some new measures should be introduced.

The number of forest guards should probably be doubled in the rhino sanctuaries, their salaries increased, and their living standards ameliorated. Means of delivering provisions to them in the field could be ensured by providing more domestic elephants, which are also needed for patrols.

In order to boost the morale of the Forest Guards, law enforcement against poaching must be improved. Too often, because of some inept public prosecutors, defendants' lawyers win costly delays in court. State witnesses are consequently requested to come back repeatedly, and since these are usually Forest Department staff, they lose time from their jobs in the field and occasionally become discouraged by the proceedings. Justice is neither swift nor certain in rhinopoaching hearings.

Only one major trader in rhino horn has been imprisoned, and middlemen seem to escape all prosecution because one of the greatest weaknesses in the Forest Department is the low level of intelligence gathering. Money is needed to pay reliable informants on the activities of wildlife syndicates. In other countries, informants have been extremely helpful in identifying middlemen in the wildlife trade. We know that middlemen are actively abetting rhino poaching in India, and stopping them would have a greater effect in reducing the poaching than any other measure taken.

In West Bengal the natural habitat around Jaldapara is the main home for this state's rhinos, but it is being rapidly destroyed and poaching is heavy. Because relations are poor between Forest Department staff and villagers, the latter sometimes support outsiders who come to kill the rhinos. Special efforts should be made to save the remaining rhino population, for this and Assam are the only two states in India with more than 10 rhinos. Co-operation between them in trying to identify and eliminate wildlife syndicates should also be strengthened. 
Although the Indian Government has provisionally allocated a large sum of money for rhino protection in Assam, more may be needed. The Forest Department might, therefore, consider selling abroad a pair of live rhinos, which are worth over $\$ 100,000$. While this idea may offend some conservationists, it should be borne in mind that rhinos from Assam have actually been given away in recent years. One method of raising funds that should not be used, however, is that of selling rhino horn. The Assam Forest Department has collected many horns from dead rhinos. At the end of June 1984 the stocks stood at 338 pieces, weighing $235.5 \mathrm{~kg}$, according to $\mathrm{Mr} \mathrm{P}$. C. Das. In South East Asia, the wholesale value of the horns would be approximately US $\$ 2,000,000$, but they should not be sold because this would encourage the demand for the horn.

The Assam Government is planning to expand some of the rhino sanctuaries, including Kaziranga. This is an excellent idea. However, in doing so, many people will have to move away from their present homes. In order to prevent antagonism, fair prices will have to be paid to the landowners, and steps will have to be taken to convince the remaining farmers on the boundaries that they themselves will have something to gain from the expansion of the sanctuaries. At present, these people benefit very little from them, and when a rhino moves on to their farms and seriously damages their crops, no compensation is paid.

Senior officers in the Forest Department have offered suggestions on how local people could benefit from Kaziranga National Park, and some of these should be acted upon. For example, a little revenue from tourism (which has increased phenomenally from 6203 visitors in $1979 / 80$ to 45,014 in $1984 / 85$ ) could be invested in improvements to schools and hospitals. Financial incentives could be given to the villagers willing to patrol their own areas and to report to the authorities strangers who might be poachers. People living near the boundary of Nepal's Chitwan Park are allowed, at a certain time of the year, to remove some of the grass inside the park for thatch, carefully supervised to prevent disturbance to the animals. This could be permitted at Kaziranga.

In conclusion, we believe that India's rhino crisis will be rectified. The recovery of the greater Indian rhinoceros population from a few dozen in 1910 to 1250 in 1980 was achieved. With additional funds, better understanding of the wildlife syndicates and closing of the international markets for rhino horn, the average annual 5 per cent loss of India's rhino population from poaching between 1982 and 1985 could be halted. India would then again have one of the best managed rhino populations in the world.

\section{Acknowledgments}

We would like to thank the following organizations for their support of the project to try to close down the international trade in rhino products: WWF, IUCN, CITES, the New York Zoological Society, the African Wildlife Foundation, the African Fund for Endangered Wildlife and the Columbus Zoo, Ohio. We are also most grateful to many individuals in India for their help. In particular we would like to thank: Mr R. Bhattacharjee, Orang Game Reserve; Mr J. Das, Gauhati Zoo; Mr P. C. Das, former Chief Conservator of Forests, Assam; Mr S. Deb Roy, Manas Wildlife Sanctuary; Mr P. Lahan, Kaziranga National Park; Mr Mukherjee, CITES, Delhi; Dr Mohamed Quraishi, Hyderabad; Dr M.K. Ranjitsinh, Delhi; Mr G. Saikia, Kaziranga National Park; Mr M. S. K. Sharma Manas Wildlife Sanctuary; and Mr D.A. Varughese, Gauhati Zoo.

\section{References}

Bhattacharjee, R. 1985. Report on First Census of Animals in Orang Game Reserve Carried Out in 1985. Unpublished.

Laurie, A. 1978. The Ecology and Behaviour of the Greater One-Horned Rhinoceros. PhD Thesis. University of Cambridge.

Lahan, P. 1984. A Report on the Census of Large Mammals in Kaziranga National Park, March, 1984. Unpublished.

Martin, Esmond Bradley, 1983. Rhino Exploitation: The Trade in Rhino Products in India, Indonesia, Malaysia. Burma, Japan and South Korea. World Wildlife Fund, Hong Kong.

Martin, Esmond Bradley, 1985. Religion, royalty and rhino conservation in Nepal. Oryx. 19, 11-16.

Esmond and Chryssee Bradley Martin. PO Box 15510.

Nairobi, Kenya.

Lucy Vigne. PO Box 48489, Nairobi, Kenya. 